\title{
Introduction: Solving the Problems of Climate Change and Sustainability
}

\author{
RICHARD B. ROOD
}

Volume 2, Fall 2014

http://dx.doi.org/10.3998/mjs.12333712.0002.002

Professor, Department of Atmospheric, Oceanic and Space Sciences, University of Michigan

In the first volume of the Michigan Journal of Sustainability, Andrew Hoffman sought to establish the rules of the game for academic engagement in the political and public discourse (Hoffman 2013). He wrote about the journal's mission to integrate and translate knowledge across many fields of science, engaging scientists, practitioners, and policymakers. I continue with these themes, focusing on integration, translation, and the role of the educator.

Recently, I gave a talk on information systems and usable science. In the past decade, I have focused on accelerating the use of climate-change knowledge in planning and management. In the academic literature, the term "usable" science has emerged to describe information that is understandable, relevant, and capable of being used by decision makers (Dilling and Lemos 2011). Usable science stands in contrast to the data and knowledge that scientists and researchers proffer as useful, but which are created in isolation from decision makers and without knowledge of specific decision contexts. My talk was drawn from an article that Paul Edwards and I wrote following our experimental class on climate informatics (Rood and Edwards 2014). In the article, we emphasize that there are many online data services and portals and that the data from these assets are often so hard to use that they are deemed unusable. This usability gap is not unique to the climate informatics field but is pervasive across the sciences. Simply put, access to data is not enough.

Access to knowledge can be framed as an extension of access to data. We naively expect that knowledge will be broadly used to address problems of climate change and sustainability, but, like access to data, access to knowledge is insufficient. It follows that simply generating knowledge is not adequate for problem solving. We need to provide information on what to do with that knowledge, as well as train- 
ing on how to use that knowledge. We need to correct "[t]he erroneous assumption ... that skills evolve naturally from knowledge" (Hines, Hungerford, and Tomera 1987).

The academic enterprise in the United States is magnificently successful at generating knowledge. Some say that the miracle of the Enlightenment and the advance of Western thought lay in the emergence of the reductionist scientific method. The reductionist approach breaks down problems into pieces, isolates them, and studies them in a controlled fashion (Wilson 1998). Reduction leads naturally to disciplinary study. Problem solving, on the other hand, requires the integration and translation of knowledge and the synthesis of that knowledge into actions. Though we talk about cross-disciplinary, multi-disciplinary or trans-disciplinary research, such broad-based research struggles to gain traction in our scientific enterprise. We do not adequately value the unification of science; we do not adequately value the integration of knowledge across fields. Therefore, problem solving is frustratingly slow.

I came to the University of Michigan in 2005 after more than 20 years at the National Aeronautics and Space Administration (NASA). NASA's mission is centered on engineering and science. At the heart of NASA's mission is problem solving, and when I was at NASA, many performance plans included the mandate, "solve complex problems with no known solutions." Through my experiences at NASA, I accumulated knowledge of problem solving, which I try to bring to my classes at Michigan. I will use my experiences at NASA to illustrate the need to synthesize knowledge and balance stakeholder interests.

My formal training was in physical science, and my initial research focused on ozone and ozone depletion. Relatively early in my career, I took on management responsibilities. This decision followed from my tendency to look at systems as a whole. Ultimately, I became responsible for building models that represent the Earth's climate. Climate models are mathematical descriptions of the Earth's climate, and they require computational systems to manage the calculations and data to replicate the climate system. The calculations contribute both to an understanding of observed properties and the exploration of how the climate will change in the future.

The Earth's climate is characterized by exchanges of energy through physical, chemical, and biological processes. These processes take place at very small scales (e.g., a daisy absorbing energy from the Sun and growing), and at very large scales (e.g., the tides that come from the gravitational forces of the Sun, Moon, and Earth). When we think of climate, we think of the atmosphere, the oceans, the land, the 
ice sheets, and the life that inhabits the planet. Often when we think of climate, we think of weather and how the weather influences the lives of humans. The challenge of understanding and predicting the Earth's climate, of calculating the budget of all of those large and small energy exchanges, is dauntingly complex. Climate models are, by necessity, simplified descriptions of our knowledge of the Earth's climate.

Even so, the complexity of climate models is far more than a single individual can manage. A climate model might be framed as an atmosphere model plus an ocean model plus models of all of the other components required to provide a credible likeness to the climate. Atmospheric science is a discipline, and within atmospheric science there are many sub-disciplines. Building a model requires bringing together the individual scientists of these disciplines, all of whom view their part of the model as the most important. They know the improvements that can be made to their part of the model, and they often assert that those improvements extend to the model as a whole. Such assertions are rarely true. Therefore, in addition to being a scientific and technical challenge, building a climate model is a social challenge. How do you get a group of scientists who have been rewarded for their individual and novel contributions to yield to the priorities of the model as a whole?

Comprehensive climate models and data systems require high-performance software and high-performance computing. These are not simply generic tools; it takes research and customization to execute the models and to support the analysis of the resulting data. Again, this requires that experts be brought together, experts from different backgrounds, with different expectations, and with different skillsets. Tension runs high in these situations, with scientists often seeing the requirements of the computational system as somehow diminishing or even damaging "the science."

In order to deliver validated scientific products on time and on budget, I ultimately studied project management, organizational psychology, and organizational governance-whatever was needed to solve the problem. Successful problem solving requires the synthesis of knowledge and priorities. Inclusion of science-based knowledge in decision making is most effectively achieved by an iterative process of co-development or co-production that manages contradictions and tensions. Problem solving requires skills in moderation, collaboration, and dynamic decision making (see Dilling and Lemos 2011).

Problem solving often requires reaching out of your area of expertise, out of your discipline, but academia awards funding and tenure for discipline-based production of knowledge. As Hoffman stated in his 2013 article, there are tensions and barriers between the rules of the game for successful academics and the elements 
of effective problem solving. This tension reaches deep, as the review process and funding practices support the successful academic more robustly than they support successful problem solving.

Let me extend Hoffman's 2013 Introduction by suggesting that there is another role for the academic in the public and political discourse - education (Cuomo 2011). At the request of students who were not scientists, I started a course on climate change that attracted a mix of students. Some were deeply expert in how particles of dust in the atmosphere influence energy exchanges. Others were acutely aware of the disruptions that climate change will cause and wanted to know how to integrate this knowledge into finance. Early in the course, I was faced with the fact that the non-scientists often knew more about the climate as a whole than the science students. What was needed was a framework for critical thinking to allow students to use knowledge from many fields in problem solving. This example also illustrates that we need to learn how to solve problems earlier, rather than later, in our lives. Sustainability and climate change are problems of the here and now, and these problems require problem solvers ready to take action on these challenges.

A unique way that universities can influence the public and political discourse is to develop professional problem solvers, translators who are prepared to break down the barriers created by disciplines and competing interests. These professionals need to take their places in the workforce and in political entities and work to bridge divides. In keeping with the mission of the Michigan Journal of Sustainability, we need to bring scientists, practitioners, and policy makers together. As you read the articles in this issue, I encourage you to think about how topics outside of your own field may actually be connected to your work, and how you might serve as a translator across fields to contribute to the synthesis and development of strategies that will address the challenges of the future.

\section{References}

Cuomo, Chris J. 2011. "Climate Change, Vulnerability, and Responsibility.” Hypatia 26 (4): 690714.

Dilling, Lisa, and Maria Carmen Lemos. 2011. "Creating Usable Science: Opportunities and Constraints for Climate Knowledge Use and Their Implications for Science Policy.” Global Environmental Change 21 (2): 680-689. doi:10.1016/j.gloenvcha.2010.11.006.

Hines, Jody M., Harold R. Hungerford, and Audrey N. Tomera. 1987. "Analysis and Synthesis of Research on Responsible Environmental Behavior: A Meta-Analysis." Journal of Environmental Education 18 (2): 1-8, 1987. http://dx.doi.org/10.1080/00958964.1987.9943482 
Hoffman, Andrew. 2013. "Academic Engagement in Public and Political Discourse: Establishing the Rules of the Game." Michigan Journal of Sustainability 1 (1): 5-13. doi: http://dx.doi. org/10.3998/mjs.12333712.0001.003.

Rood, Richard B., and Paul N. Edwards. 2014. "Climate Informatics: Human Experts and the End-to-End System.” Earthzine. http://www.earthzine.org/2014/05/22/climate-informaticshuman-experts-and-the-end-to-end-system/.

Wilson, Edward Osborne. 1998. Consilience: The Unity of Knowledge. New York: Knopf, 352. 